\title{
Empowering Non-licensed-in-English Language Teachers to Construct Professional Knowledge in Their Actual and Imagined Communities of Practice
}

\author{
Edgar Augusto Aguirre-Garzón ${ }^{1} \&$ Harold Andrés Castañeda-Peña ${ }^{2}$ \\ ${ }^{1}$ Pontificia Universidad Javeriana, Bogotá, Colombia \\ ${ }^{2}$ Doctorado Interinstitucional en Educación, Universidad Distrital Francisco José de Caldas, Bogotá, Colombia \\ Correspondence: Edgar Augusto Aguirre-Garzón, Pontificia Universidad Javeriana, Transversal 4 \#42-00, \\ Colombia. E-mail: hedgarhagui@gmail.com
}

Received: May 22, 2017 Accepted: July 9, 2017 Online Published: July 11, 2017

doi: 10.5539/elt.v10n8p78 URL: http://doi.org/10.5539/elt.v10n8p78

\begin{abstract}
Research has accumulated important knowledge over recent decades on how licensed language teachers develop and learn from cognitive and socio-cultural stances. Yet, relatively little evidence exists on how non-licensed-in-English language teachers (NLELTs) grow professionally in their communities. Similarly, few studies have yet investigated the concept of "imagined communities" in the language teaching field with these particular types of population. This study attempts to fill this gap by exploring the possible forms of professional knowledge that NLELTs build through participation in the activities of a learning community. Four non-licensed language teachers participated in a nine-month collaborative-reflective process focused on language teaching practices, in a public school in Bogotá (Colombia). In analyzing their interactions and consequent products, we discuss three dimensions of knowledge construction propelled by the individual visions they brought into the community. Furthermore, we analyze how learning in that present community granted the teachers access to envisioned practices in imagined communities for a desirable future. Based on the findings we argue that success or failure in participation in present, real communities determines imagined affiliation to future communities, their practices and even the NLELTs' preferred future positionings as professionals.
\end{abstract}

Keywords: collaboration, communities of practice, imagined communities, non-licensed-in-English language teachers, professional development

\section{Introduction}

\subsection{Contextulization of the Problem of Study}

In the language teacher education field, there has been an increasing interest in strengthening the quality of teacher education programs, as well as a focus on furthering the professional development of teachers in Colombia. There is, however, little evidence about how English teachers, who do not have a degree in language teaching, develop professionally.

The dynamics of the language teaching phenomenon in Colombia has diversified this field from a professional point of view, allowing professionals in other areas the entrance to the labor. In this sense, it is pertinent to analyze how English teachers, who have not majored in any of the language teaching-related fields, confront those dynamics by working with peers and learning in their contexts. This article presents the results of a collaborative inquiry process that four non-licensed in English language teachers (NLELTs) engaged in, during a nine-month period in a public school in Bogotá, Colombia. The collaborative work started as a result of the need to agree on solutions to help students meet EFL (English as a Foreign Language) curricular goals in the school. The analysis of the process not only demonstrated traces of the teachers' professional learning and their construction of pedagogic knowledge through their engagement in a community of practice (Wenger, 1998) established in the school, but also, as participants of their future imagined communities (Kanno \& Norton, 2003), they constructed imagined versions of themselves, for a better professional future.

The study interrogated potential forms of professional knowledge constructed by four NLELTs through their participation in a collaborative learning community. The objective of the investigation was to analyze and 
describe traces and forms of professional knowledge that were socially constructed in the heart of a community of practice through collaborative actions that the four participants developed themselves (as no collaborative purposive agendas were imposed).

Academic literature on the professional development of teachers has not sufficiently investigated how NLELTs learn, acquire and construct knowledge during their in-service careers. One of the strongest implications of this research report is that a teacher's knowledge cannot be framed in a particular teacher's mind but is a sociocultural and historical construct that is constantly evolving (Diaz-Maggioli, 2012). This means that a teacher's knowledge should no longer be seen as something constructed individually but as the result of social interaction with agents involved in the act of teaching (Diaz-Maggioli, 2012).

In recent years, the development of teacher knowledge has focused on the role of collaborative models dialogically oriented, that foster the co-construction of knowledge among teachers (Clarke, 2003; Cochran-Smith, 1993; Darling-Hammond, 2006). The perspective of knowledge construction through dialogue and interaction among professionals is mediated by a teacher's participation and contributions in a community of inquiry (Harteis \& Gruber, 2004; Paavola, Lipponen, \& Hakkarainen, 2004) or in a community with shared practices (Lave \& Wegner, 1991) where learning is proportional to the type and quality of participation in the activities of the community. This is how research has acknowledged models of professional development that are grounded in collaboration in communities of inquiry as an important means by which to hone a teacher's professional growth (Cobb, Confrey, diSessa, Lehrer \& Schauble, 2003).

\subsection{Non-licensed-in-English language Teachers (NLELTS)}

Contemporary research demonstrates that teachers in general are responsible for the success or failure in students' achievement. Although our paper is not aimed to compare or contrast the impact of development of licensed and non-licensed teachers, we acknowledge that some of those studies might contribute to the understanding of the phenomenon described in our study. A number of those investigations, for example, contend that teachers, who meet professional teaching standards in certain countries, are superior in promoting academic achievement over those who do not meet such standards (Vandevoort, Amrein-Beardsley, \& Berliner, 2004). Conversely, Widodo (2017) reports in his study that in Indonesia, teacher certification programs do not necessarily lead to teachers' high competences in teaching. In this sense, the author suggests that it is important to consider subjective factors, such as the type of pedagogical-content knowledge (PCK) that cannot be strictly measured by standardized systems. Such is the specific case of Minnesota special education teachers, who although being licensed teachers, they report being ill-prepared to provide the necessary instruction needed by students with reading disabilities. The author proposes coaching as an effective form of professional development which supports classroom instruction (Papineau, 2017).

In order to conceptualize the term NLELTs we draw on Karimi's (2011) conception of non-licensed teachers as the teachers who have not majored in any of the English-related fields but have learnt English in other contexts like institutes. These teachers have entered teaching through nonconventional routes and may have strong content backgrounds but less general education training, or the other way around. They may not have taken any EFL pedagogical courses and rely principally on their subject matter knowledge (Karimi, 2011).

Research investigating professionals in other areas entering the field of language teaching, concern by and large on the particularities of contexts that prompt institutions to recruit them (Akbari \& Moradkhani, 2012; Cheng \& Wang, 2004). Other studies have looked into understanding the lived experiences of other professionals who choose to become language teachers as they form identities as ELTs (Trent, Gao, \& Gu, 2014). Albeit this body of knowledge, little emphasis has been given to comprehend how NLELTs construct professional knowledge in their communities, develop and project themselves professionally in imagined communities of practice. We attempt to delve into those processes in this study.

To begin making sense of what development entails, we want to gather the conceptualizations of authors who have focused their research on teacher education and professional development (PD). Richards and Farrell (2005), for instance, contend that PD refers to a general growth, prorogued over a relatively extended period of time, which facilitates a teacher's understanding of teaching and of themselves as language teachers. These authors also argue that development has to do with examining different dimensions of a teacher's practice as a result of their reflective review.

Similarly, Diaz-Maggioli (2003) agrees that PD is an evolving process which teachers choose to willingly participate in order to learn how to appropriately fit teaching practices to their learners' needs. Cárdenas, González, and Álvarez (2010) reinforce the idea of teachers taking part in development processes in order to obtain better results in practices. 
In general terms, PD is grounded on fundamental characteristics such as being a career-long process in which teachers attune their teaching to student needs. It is of special interest in this paper to explore how NLELTs develop professionally in their contexts. Such inquiry is explored below.

\subsection{NLELTS Learning and Development}

The discussion about how NLELTs learn about teaching and develop professionally emanates from the conception that teachers are "active, thinking decision-makers who make instructional choices by drawing on complex, practically-oriented, personalized, and context-sensitive networks of knowledge, thoughts, and beliefs" (Borg, 2003, p. 81). It is argued that NLELTs also resort to their personal epistemology (Hofer, 2001) consisting in their own theories and beliefs about knowledge and knowing, which originate long before from their experiences of being students (Weinstein, 1990) and of being professionals in other fields. Since NLELTs' contact to formal language teacher educational programs is arguably not existent, they might generate knowledge and construct their own explanations of what works and does not work in their classrooms (Shin, 2016).

Consistent with sociocultural theories that focus on social nature of cognition and learning, it is deemed that NLELTs might develop professionally by participating in social practices with other professionals. Those practices can take the form of informal mentoring, peer coaching and reflective teaching.

Mentoring can be seen as a means of educating teachers without expertise in their initial experience in teaching, through the concept of role model. It can be carried out formally or informally between more experienced teachers (mentors) and teachers with little or none experience in teaching (mentees). Mentoring is an excellent tool for professional learning for both the mentor and the mentee through systematic critical reflection (Carmin, 1998). Sustained involvement in mentoring provides non-licensed teachers with opportunities for enhancing skills in favor of instructional change (Diaz-Maggioli, 2004).

Peer coaching can be defined as "a professional development method that had been shown to increase collegiality and improve teaching" (Gailbraith \& Anstrom, 1991). In this expertise sharing process, NLELTs can benefit by obtaining feedback, support and assistance from supportive peers to refine skills, learning new ones and/or solving classroom related problems. Since peer coaching is a conventional model related to a transmission model of development, it supports the idea that teachers need to be fixed, leaving little room for a version of teacher growth focused on what teachers need (Diaz-Maggioli, 2004).

Finally, reflective teaching is understood as the process of critically examining practices in order to have a better vision of one's own teaching dynamics (Richards \& Lockhart, 1994). This process can be achieved in isolation or in collaboration with other colleagues.

\subsection{Models of Professional Development and Teacher Education}

Several authors have paid attention to how English language teachers can continue to develop their professional aptitudes once their formal process of education has finished. This need for ongoing learning has brought the design of models of development into consideration, based on practices such as reflective practice, collaboration and team teaching.

On the one hand, in 1991, Wallace conceived a model in which he viewed development based on the assumption that teachers learned by analyzing their teaching experiences in an introspective and retrospective manner. This process is known as "reflective teaching" and has been the basis of a teacher's professional learning for decades (Schon, 1983; Wallace, 1991).

Richards and Farrell (2005) propose another model of PD that according to Cárdenas et al. (2010) is characterized by a dual dimension. The first one, the institutional, consists of the sort of efforts in which institutions need to engage so as to improve the academic and formative conditions of teachers in schools or universities. The second is the individual dimension that is related to aspects of individual knowledge and awareness in teachers, namely, knowledge of the students, metacognitive processes, disciplinary knowledge, pedagogical knowledge and knowledge of the curriculum. This model, in which these two domains are directly integrated, searches for an improvement in the educative processes and hence requires teachers to update their knowledge.

Alternatively, James (2001) suggests that a good model of PD should be aimed at promoting teacher development in a holistic way. There are three main constructs that characterize James' (2001) model: personal, disciplinary and educational. Some components depicted in this model of PD, involve domains such as teacher identities, which suggests that they are individually, but most importantly, socially constructed. This socio-cultural conception of identity construction has been thoroughly elaborated by different advocates like Norton and Toohey (2002) and Ivanic (2006). 
Much of the aforementioned work has constituted the cornerstone of PD proposals and models by researchers in Colombia. One example is the work carried out locally by McNulty and Quinchía (2007), in which they subscribe to James' (2001) view of holistic learning, in this case, for elementary in-service teachers. In a nutshell, the program designed by McNulty and Quinchía (2007) focused attention on the necessities of the participants as far as their educative realities and the possibility of participating in curricular construction starting from their learning process. One of the interesting outcomes of this study was that teachers started to take risks regarding the selection of different methodologies for their practices, which they explored during the PD program.

\subsection{Four Traditions in Teacher Learning}

One dimension related to how teachers learn, to which we subscribe, is the socio-constructivist vision mapped out by Diaz-Maggioli (2012). The author makes distinctions between teacher education and professional development as "two sides of the same coin". On the one hand, teacher education has to do with a teacher's knowledge base (skills, mastery and dispositions), and on the other, the ability to use those elements to further quality teaching "which may result in quality learning" (Diaz-Maggioli, 2012, p. 7). His perspective is elaborated in light of four traditions of teacher learning. The first one is look and learn, which he also calls "the craft tradition" (Wallace, 1991). This tradition consists in seeing the teacher as an apprentice who acquires knowledge, as a result of instruction, (such as knowledge related to methods) to apply in any teaching situation, regardless of the particularities of the context.

The second tradition, read and learn, also called "the applied science tradition", sees the teacher as a reader of theory to consequently incorporate into their practice. In other words, this vision conceives of teachers, as Kumaravadivelu (2006) points out, "consumers of knowledge". The third tradition, think and learn, is grounded in Schön's (1983) work on reflective practice. Within this tradition, teachers are seen as researcher practitioners who fundamentally focus on research anchored on reflection of their practices and actions.

Finally, the last tradition of teacher learning, participate and learn, constitutes the epistemological basis of the teacher development perspective proposed by the research study in this article. This sociocultural perspective, as Diaz-Maggioli (2012) defines it, envisages teachers as active participants in the practices of communities, or communities of practice (Lave \& Wenger, 1991) that are made up of professionals of different levels of expertise and experience.

According to Lave and Wegner (1991), learning is determined by the degree and dynamics of participation in the activities of the community. Initially, when someone is a newcomer to the community, they begin as a peripheral legitimate participant. Old-time members modify their activity to make way for the new member. Over time, new participants move closer to full, legitimate participation as they gain knowledge and learn the community's customs and activities and re-dimension the view of themselves as members of the community (Lave \& Wenger, 1991). Nonetheless, in this study, the participants are "co-founders" of the same community they constituted; hence, the dynamics of participation are described as they construct knowledge together.

Additionally, the participate and learn tradition is not just the cognitive process of acquiring a set of skills and knowledge, but is part of a more complex, dynamic process of changing participation patterns in various communities with shared practices. In other words, "learning is seen not as the property of an individual's mind but as the collective endeavor of a community engaged in developing a specific practice" (Diaz-Maggioli, 2012, p. 12). This idea also encapsulates epistemological stances such as professional knowledge (related to theories and procedures), personal knowledge (drawn by experience), and community knowledge (engaged in practices of the community) in order to contribute to the shaping and re-shaping of community member understandings through their involvement in teaching and learning practices (Diaz-Maggioli, 2012).

\subsection{Imagined Communities of Practice}

The participate and learn perspective described by Diaz-Maggioli (2012) and inspired for the most part by the work of Lave and Wegner (1991), has progressively gained attention in the fields of education and applied linguistics (Toohey, 2000). Nevertheless, there is more to consider when making sense of the epistemological groundings of community membership. As Wenger (1998) also suggests, engagement, understood as a direct involvement with community practices and investment in tangible and concrete relationships, is not the only way in which we belong to a community. Imagination, "a process of expanding oneself by transcending our time and space and creating new images of the world and ourselves" (p. 176), is another important source of community affiliation. We can imagine ourselves bonded to a community beyond time and space with people we have not yet met and practices we imagine participating in; ergo, we invest in the present to be part of such community. This conception of communities was called the "imagined communities" by Anderson (1991), and refers to groups of people, not immediately tangible and accessible, with whom we connect through the power of the 
imagination (Kanno \& Norton, 2003).

Some authors working in different educational contexts have conceptualized the term "imagined communities" as proving that there is a real capacity in humans to connect to imaginary communities, regardless of aspects such as time and space. Nevertheless, little research has been conducted on NLELTs' learning connected to learner participation in the wider world. Kanno and Norton, (2003), for example, have worked on extending the notion that learner affiliation to imagined communities might affect their learning trajectories. In the same vein, Pavlenko and Norton (2007) incorporated the concept into the study of second language learning and education, arguing that "learners have different investments in different members of the target language community", and that "the people in whom the learners have the greatest investment may be the very people who provide (or limit) access to the imagined community of a given learner" (p. 592). The authors have investigated how, based on the previous assumptions, desired memberships of language learners in various imagined communities mediate the learning of - or resistance to - the practice, in that case, of English. In this paper we were also interested in investigating how these foci of knowledge on imagined communities and imagined practices overlap language teacher learning dimensions.

So far, some conceptualizations of models for a teacher's PD have been presented as a way to construct professional learning. Some traditions of how teachers learn have been portrayed, following the idea that learning leads to PD. We emphasized a sociocultural situated form of professional learning based on Lave and Wegner's concept of communities of practice. Then, we extended to a comparable possibility proposed by Wenger (1998) and Anderson (1991) of using imagination as another means of engagement with other intangible, but no less real, communities of practice, known as imagined communities.

Although some authors have investigated the role of learning processes in communities of practice and imagined communities, little has been explored in language teacher learning - let alone NLELTs' learning - , as connected to their participation in other imagined worlds. In this way, we set a backdrop of theory oriented to underpin the main tenets of the research study reported in this paper. In the next section, we will elaborate on the methodological approach of the research study.

\section{Method}

This section presents the research design and describes the participants who took part in the study, as well as the instruments used for the collection of data.

This case study employed qualitative descriptive and interpretive characteristics in order to answer the research question. This design is the one that better fits the investigation since we wanted to describe a phenomenon occurring in a natural setting (Merriam, 2009). The phenomenon to describe is the form of professional learning that a group of teachers use as part of a process of collaborative inquiry in a community of practice in which they participated. Nevertheless, these teachers faced some situations, such as the implication of limited language teaching instruction and/or disciplinary knowledge (or lack thereof) in their practices, considering they are not licensed English teachers, and the lack of professional communication opportunities that could help to deal with the implications of those pedagogical limitations. We wonder what possible forms of professional knowledge can be achieved by the teachers through socializing experiences and sharing knowledge in a community of practice.

\subsection{Context}

The study took place in the Morning Star Public School (name changed by the researchers) located in southern Bogotá. The school offers levels, according to the Colombian system, for basic education (five grades of primary and four grades of secondary), high school education (two grades and ends with the bachelor's degree). The curriculum has a constructivist vision that intends teachers to develop communicative competences in students by teaching language in a meaningful way, taking into account the students' needs and motivations.

\subsection{Participants}

The research participants in the study were four English teachers, three females and one male, whose ages ranged between 26 and 39 years old. The teachers have been in service for five to eight years. One female teacher, Sue, holds a bachelor degree in Child Education. The two other female teachers, Pam and Anne, hold bachelor degrees in Spanish Literature teaching, and the male teacher Geoff is a psychologist working as a language teacher for primary courses. The female teachers took an English course as a requirement to teach English classes. The psychologist teacher learned English by himself and also traveled to the United States for some time. He became proficient in the language. All NLELTs were considered as being able to teach English by the school's authority. In the Colombian system, professionals without a teaching degree can access to the teaching public system, according to decree 2277 of 1979 issued by the Ministry of Education. This means that 
school authorities are allowed to place teachers according to their expertise and schools' needs, regardless of professionals' disciplinary field.

Convenience sampling was used to purposefully select the participants since they were readily available. Most importantly, we wanted to have a sample of teachers who did not hold a degree in teaching languages, for the sake of the issue under investigation.

\subsection{Procedures}

The inquiry process was based fundamentally on collaborative meetings that lasted two hours each, and took place every two weeks. The meetings were audio-recorded during nine months, which made roughly 18 in all. During the encounters, the participants had the opportunity to share knowledge and potentially construct new one. Following the meetings, the NLELTs participated in interviews and also wrote journals.

The interviews were semi-structured and contained questions elaborated upfront, related to the NLELTs' perceptions, analyses and sentiments about the achievements and failures occurred during the collaborative meetings. Although we utilized the question guide as interviewers, the conversations followed topical trajectories when we considered it appropriate. In total, four semi-structured interviews were done during the process, with two different key informants each time. They were administered in the first, third, sixth and nine month of the implementation, in order to maintain a regular periodicity. As far as the journals, they were written by the NLELTs every two weeks, after each meeting. The journals embodied the NLELTs' reflections upon what they gained from the collaborative meetings and the impact in their practices.

\section{Data Analysis}

In this section, we will present the analysis and findings that show the forms of professional knowledge that the four participants could collectively construct by engaging with the practices of a professional community. In order to understand how those construction dynamics took place, we consider relevant to first analyze the re-constructions of knowledge that the teachers bring into the community from the outset of the process. We present and describe the different forms of professional knowledge constructed through participation in which the participants engaged and that comprise the core data to respond the research inquiry. Finally, we will elaborate on two angles directly related to the findings derived from participation for construction of knowledge, namely the transformations through participation resulting from this collective enterprise and the imagined future participation that the teachers envision carrying out as empowered subjects in an evolving community of practice.

The data drawn and utilized for this analysis was obtained primarily from the interactions of the NLELTs in the collaborative encounters. The conversations, which were held in Spanish and translated into English, were audio-recorded and transcribed as verbatim as possible. Information was also collected from teacher journals and interviews.

Most of the coding was carried out using the software Atlas.ti. During this process, the research question was taken into account at all times, relating categories and properties to each other, via combination of inductive and deductive thinking (Corbin \& Strauss, 2015).

In order to describe the forms of professional knowledge achieved by the teacher participants, it was necessary to observe the teachers talking in the collaborative meetings. That is, what emerges from the interactions among teachers indicates that there is meaningful collective learning or that opportunities for learning are created (Diaz-Maggioli, 2012). We thus decided to identify the moments of negotiation during talk which are defined as units of analysis where teachers engage in the focused discussion of a particular teaching practice (Liu, 2013).

\section{Findings}

The initial part of the analysis consists of presenting the reconstructions of knowledge that the teachers bring to the community of practice (CoP) as peripheral legitimate participants, that according to Diaz-Maggioli (2012), is characteristic of the participate-and-learn perspective. The author argues that the newcomers need certain knowledge in order to participate in the practices of the community. This knowledge is accumulated by community members before their arrival in the community and is eventually reconstructed with other members through dialogue.

\subsection{Members' Reconstruction of Knowledge}

During the initial state of the collaborative meetings, the interactions of the participants revealed three types of knowledge that they brought to the community of practice: a teacher's experiential knowledge, a teacher's personal knowledge and a teacher's professional knowledge. They were categorized under the term "Members' 
reconstruction of knowledge".

A teacher's experiential knowledge is the result of previous effective or ineffective teaching practices that are consequently socialized with the other participants in the collaborative meetings. This aspect is demonstrated in the following excerpt from a transcription of a meeting in which Anne and Pam talk about the ways they proceed to start a class:

A: "I start my class with an exploratory activity. For example, with numbers, I give them the image of a forest where the numbers are hidden. Then they should find them in the forest and the point is that they recall them. Only after that, I go on to explain and at the end, they write the numbers." (Meeting transcript. 41)

P: "Well, I always start with a revision of the previous class. So, I ask them what they remember; they normally recall it because I use the same questions every time or I simply remind them what we did last time." (Meeting transcript. 42)

It is evident that the teachers have different ways to start a class, which they have adopted as a result of experience. This experiential learning could be the result of empirical choices or the replication of practices seen in other licensed language teachers. This last assumption relates to the look-and-learn tradition mentioned in this paper, supporting Diaz-Maggioli's (2012) theory that, in order to participate in a CoP, teachers need to be grounded in the three traditions discussed in the review of literature.

A teacher's initial experiential knowledge is used by the community members during meetings to promote opportunities to participate in the construction of new knowledge. This excerpt from Pam's intervention supports this view:

P: "I also worked on that topic last year. So I told them to bring in magazines, clippings and cuttings of people, so it was like... and I first reviewed the questions with them, so I said to them: alright we are going to start off with the face..." (Meeting transcript. 45)

As the NLELTs encountered the locus of collaboration in the learning community, this was used to strengthen the quality of classes, as they initially struggled with the way to start designing such lessons. The contribution in the sample above demonstrates how Pam resorts to her experience in teaching the same topic, to contribute to the design of a plan for a class about adjectives in English.

The second type of knowledge, a teacher's personal knowledge, refers to the understanding that the NLELTs have of themselves as teachers. That knowledge of themselves as professionals can be equated to a self-positioning in the community, which is observable through discursive acts of positioning (Correa, Martinez-Arbelaiz \& Aberasturi-Apraiz, 2015).

This knowledge of themselves as self-positioning can be seen in the samples below. In the first one, taken from a dialogue between teachers, Sue describes how she sees herself as knowledgeable in front of her students. The second is an excerpt from Geoff's journal where he notes his reflections on a collaborative session:

S: "My problem is that as I am not a fluent English speaker, for example, I search for mechanisms for them [the students] to improve their listening [skills] because I find that important".

G: "I find it easier to plan a class when there are points of view, objectives or activities in common, as in Sue's and Anne's case. In my case, not only do I have a different course but also I have some differences in the way I achieve my goals, which makes joint planning more complex". (Journal transcript. 12)

Opportunities to learn, how teachers learned and what was learned in this community were also influenced by the way the NLELTs self-positioned as language teachers. That meta-cognition of the self that is brought into the dynamics of a community of practice can be seen, as Schneider and Kipp (2015) assert, as a mediating factor that might foster or hinder the implementation and prolific functioning of a learning community and associated professional development.

The last type of knowledge, a teacher's professional knowledge, has to do with the theoretical knowledge that teachers have from relevant professional literature and that they eventually apply in the language classroom. This type of knowledge is associated with Diaz-Maggioli's (2012) read-and-learn tradition in teacher education, which conceives a teacher's knowledge of theory as the main fodder for practice.

The following excerpts taken from an initial interview with Sue and Geoff, at the beginning of the collaborative process, shed light on the theoretical type of knowledge that teachers had, as a basis for starting to participate in this community.

S: "Children learn by interacting with the social setting, which is Vygotsky's story. So then, we were told that the 
child, when interacting with other children, was learning new things, and that if one as a teacher wants to teach them something (...) they have to "anchor the new knowledge"".

G: "I got sucked into this thing of teaching because I believe 100\% that mnemonics is a unique way to learn anything, because I have witnessed it..." (Interview transcript. 3)

These conceptualizations of the teachers demonstrate that, even though their knowledge base formation as far as theories of language teaching and learning is not grounded in a language-teaching career, they still possess a professional knowledge related to education and learning that they employ to navigate through their English teaching practices. These fixed images are sometimes difficult to modify (Sanchez, 2011). Nevertheless, professional development models should seek opportunities for teachers to not only share, but also contest and dispute, such prior images of teaching and learning in order to foster the building of a more solid and co-constructed knowledge base (Veirty, 2011).

In this section of the data analysis, we contended that from the perspective of CoP, in order to analyze the dynamics of participative learning, it is relevant to understand firstly the form of a teacher's knowledge, conceived as a multidimensional and multilayered construct (Borg, 2006) that they initially bring into the process. Those types of knowledge might subsequently evolve as participants interact with other agents in the community, helping to the construction and reconstruction of new understandings of language teaching and learning (Diaz-Maggioli, 2012).

In the following subsection, we present the category that helped to describe the forms of professional knowledge that the four NLELTs engaged with in this community of practice, which is the main inquiry of the study reported in this paper.

\subsection{Forms of Professional Knowledge Constructed through Participation}

During the process of collaboration between four NLELTs at the Morning Star School, three types of knowledge constructed through participation were demonstrated: Participation for construction of didactic knowledge, Participation for construction of procedural knowledge and Participation for future improvement.

In order to obtain meaningful evidence of a teacher's participation in construction of knowledge, it was necessary to identify the moments of interaction and negotiation in the talk where teachers engaged in focused discussion of a particular aspect of lessons. For that reason, the samples of data describe the interventions of two or more teachers when possible.

The first category, participation for construction of didactic knowledge, refers to the opportunities to share, suggest and co-construct didactic alternatives to implement in language classes. In the following segment of talk, Sue and Anne found that they had the same topic for their class; the modal verb can/can't, so they agreed to prepare it with the help of the other colleagues:

S: "We have to get the images. I think we can make a Powerpoint."

A: "I was thinking of designing a slide".

S: "I mean, I gotta stick a picture of the super hero and I write the phrase below about something he can do".

“...Let's do something. Since I am not good at writing sentences, I stick the pictures, the background and stuff and you write the sentences".

A: "All right, deal. So, let's do this together".

This piece of interaction shows that Sue and Anne engage in the sharing of ideas through discussion and dialogue, a known feature of CoP according to Correa et al. (2015), to design didactic alternatives for the lesson, which happens to be the same for both participants. In doing so, Sue considers herself a teacher with limited abilities in the language but invests in the participation to design better didactic materials with her peers.

In the next segment of dialogue, the teachers are helping with the planning of Geoff's class on the demonstrative "this/that/these/those" in first grade. The conversation centers around the fact that Geoff considers it inappropriate to teach writing skills to 6 to 7 -year-old children in a second language. His colleagues try to provide teaching alternatives for his class.

G: "I wouldn't take that risk (...) I haven't taught that, I have never taught children how to write in English. Teaching a child how to write in English is the most complicated thing in the world."

S: "Then, don't make them write but give them a written guide for them to stick and color."

A: "Yes, something like dotted images, some guides with images that are like dotted and then they link the dots 
forming letters. And as they link the dots they form 'this and that'. They are not going to write anything; they are just going to connect the dots."

The literature has demonstrated that whenever teachers engage in collaborative practices with other members of the community, they share a common repertoire of knowledge (Wegner, 1998). This section of dialogue in this specific CoP, however, shows that beliefs and a repertoire of didactic knowledge sharing, is not always harmonious. The process of participating in the construction of knowledge requires that teachers contest their preconceived ideas and theories. As teachers are empowered, they have the ability to become teachers of teachers, that is, to re-orient conjointly their own and other members' repertoires through engagement in the practice. This constitutes a determinant characteristic of the tradition "participate and learn".

Participation for the construction of procedural knowledge has to do with opportunities to construct knowledge related to the way teachers think that classes should be structured, by means of establishing procedures for language teaching. The following section of dialogue extracted from a collaborative meeting, portrays the dynamics of joint work that were oriented to help Sue organize a lesson about telling time. It can be seen here that the teachers are mindful not only of the materials to use in class, but also about setting the organization of activities for a successful practice.

P: "Show them how it's done and then have them do it themselves."

A. "So you start with the easy part that is the "O'clock time""

G: "It is necessary to use a clock. That is important."

A: "Yes, of course."

S: "Ok, so I will have to make one [clock] of cardboard."

G: "No, I have one out of order in the classroom. You can use that one."

S: "Great, now I have a clock."

In this form of participation, the teachers who are actively helping Sue make suggestions in the form of commands, which entail action to be accomplished. This action does not suggest that Sue is the only one in charge of the results of the planning. Data demonstrate that the NLELTs invest in the products and take responsibility for the consequences of the decisions made in the process of planning together. We claim this evidence is the result of legitimate participation where a teacher's empowerment allows them to adopt a community-membership sense rather than an individual orientation (Buysse, Sparkman, \& Wesley, 2003).

Participation for future improvement refers to the moments in which the teachers take part in the learning community in order to promote future opportunities to carry out pedagogical improvements, as a result of reflecting on the implementation of the collectively designed ideas.

S: "For example the topic. Sometimes I see the topic is one thing, the achievement is another and the achievement indicator is another different one."

A: "Yes, it is necessary to revise that."

G: "Yes we need to re-think that matter. I believe that we together can make suggestions for next year, according to what everyone thinks."

In this extract Sue perceives that the objectives of the English area in the school are unclear as she does not know exactly what the students are meant to achieve on her course. This opinion is shared by the other three teachers who feel galvanized into taking action to re-structure those curricular aspects for next term in the yearly committees organized at the school, where representatives of the teacher's community take part in the decisions. According to Buysse et al. (2003), situated learning manifests in communities of practice in several important ways. For instance, "in a community of practice, shared inquiry and learning is centered around issues, dilemmas, and ambiguity that emerge from actual situations in authentic practice settings" (p. 267). This is more evidence of a teacher's empowerment to move towards having a bigger impact in the community, triggered by problematizing dilemmas found in the process of inquiry about practice.

The forms of participative learning formerly described led to two important ramifications that are derived from the real practices in which teachers engaged. One has to do with transformations through participation and the second with imagined future participation, which draws on the NLELTs' achievements in the CoP to envision new imagined collective participation in the future.

The category transformations through participation is associated with transformative initiatives on a professional and/or pedagogical level resulting from the participatory activities in which the NLELTs engaged 
when taking part in the CoP.

In the following excerpt from Geoff's journal, it is noticeable how the knowledge constructed with the other teachers not only enriches language practices but also that new knowledge could be applied in other teaching practices:

G: "I have practiced some of those things with my children. Not only in English lessons but in other courses and, man, that's super! All the things I've learned! So, I believe that we actually have the knowledge but each one of us has it in our isolated little islands." (Journal transcript. 5)

In the intervention, Geoff suggests that there is a basic pedagogical knowledge that every teacher has but that it is in isolation if teachers remain in isolation. It can be inferred that the nature of this knowledge is to be spread and shared with others.

In the next excerpt from Sue's journal it is seen how the participants gauge the transformations reflected not only in their pedagogical awareness but also in the way they position students in the classroom:

S: "At a professional level, for example, one realizes that when one plans the class in isolation you go like: I can't do this or I can't do that, never mind, maybe next time. But when we plan together you go like: I have to do it fully because we did it together."

"When you fulfill the whole planned class then you realize that children somewhat change their intellectual level (...) you go see and check and children are truly making some headway". (Journal transcript. 4)

From a professional stance, the transformations carried out are enacted in the ways that the teachers re-visited, and eventually shaped their visions of themselves through the teaching practices resulting from participation in the CoP.

G: "Opposite to the way I thought, she [one student] was making associations with the way the word was written. I mean, because there is no way they could know how to pronounce "spider" if they were not reading over there [on the board]. So, some children managed, according to what you said and contrary to what I thought, to grasp the written form of the words". (Journal transcript. 6)

Geoff's reflection took place after a lesson planned collaboratively, in which the other teachers suggested that he taught first grade children the way the vocabulary was written in English. Conversely, Geoff showed his disagreement with presenting vocabulary in written way during the planning process, as he had never done it before, due to considering it counterproductive for young learners. In the excerpt, Geoff came around when he proved to himself in a lesson that it was beneficial for children to know how the words are written for assimilation and pronunciation reasons. Although it might seem a minor shift in Geoff's professional knowledge repertoire, the evidence sheds light on the potential fertile ground that learning communities represent for re-dimensioning individual and collective teaching knowledge that promotes pedagogical transformations in situated contexts.

Finally, the last category resulting from this analysis is imagined future participation. Drawing on Lave and Wenger's sociocultural perspective, which associates learning with social participation, and supports the main discussion of this work, we also drew on Norton's (2001) notion that an individual's learning is not only influenced by their current social participation but also by their future affiliations to imagined CoP.

Within this category, we gathered the occasions in which the four participants of this study projected imaginary, collective participation within an imagined prolongation of conformed or new $\mathrm{CoP}$ in the future, an aspect of imagined communities in language teacher education that we contend should be studied across contexts more deeply in the future.

The following example reveals how actual participation in the construction of knowledge leads to a teacher's investment in imagined collective participations. This suggests that teachers envision themselves as belonging to a, perhaps, prevailing CoP that they imagine continuing to taking part in the future.

A: "Let's design the material together."

G: "That also sets a precedent for the next year for example, great! Doing all the material together, whoa, pretty neat! Initially for the English area."

The following segment from a conversation in a collaborative meeting illustrates a future desire to form a team in order to reconfigure the program corresponding to the English area, based on the process of collaboration.

G: "The next year we need to make up a team... I mean we already have it (...) we need to procure that English especially in primary courses (...) we need to redesign those competences in the program, those goals." 
P: "Let's reform the English area the next year."

A: "Yes, let's redesign that program."

P: "We need to get together to reform the program."

The example is in agreement with the theoretical stance assumed by Kanno and Norton (2003) who argue that a learner's "hopeful imagination" informs particular endeavors and initiatives for a better future (p.244).

Evidence of investment in future participation to form a new imagined community of learners, a community of specialized teachers, is shown in the following excerpt, captured from a teacher's oral exchange.

G: "The thing is that there is a problem in elementary courses. There are not many so to say, specialized teachers. Actually, I think there are only two in the school. Therefore, we can say there is no specialization in primary school but there are things we need to consider. This means several things. We need to prepare ourselves, and it implies that a little group of teachers should be formed."

This NLELT believes that one of the factors that might benefit pedagogical processes in the area is the existence of specialized teachers, that is, teachers who have specialized knowledge of teaching English. The fact that the NLELTs are aware that they are not specialized does not mean that they cannot attain such a categorization. What is more, Geoff believes that subscribing to an imagined community in the future will potentially provide them with the preparation to become more specialized in their field. Once again, the teachers are empowered through imagined participation not only to change pedagogical realities but also to re-position themselves as better professionals in the future.

This final analysis of how the teachers envision future imagined participation, expands from the existing idea that learners have images of communities in which they want to participate in the future (Kanno \& Norton, 2003; Pavlenko \& Norton, 2007). We suggest that because of participation in knowledge construction in an actual community, the NLELTs could imagine themselves not only belonging to imagined communities (or to existing communities that they imagine extend into the future) but also participating in imagined future practices prompted by the desire to provoke curricular changes, re-positioning themselves as professionals and pedagogical transformations.

\section{Discussion}

As the data in this particular learning community made up of four NLELTs were analyzed, we found evidence that there were three main forms of professional learning constructed by the participants, which are fundamentally centered on the design of didactic alternatives to teach English more effectively. Alternatively, there is information that supports and shapes the aforementioned findings, namely, a teacher's prior knowledge that is shared, and the hoped future transformations and participation in potential learning communities.

Anne, Geoff, Sue and Pam formed a collaborative group of teachers moved by the necessity to establish more meaningful, professional bonds. They initiated their activity in this community on the periphery (Buysse et al., 2003), because of their status as NLELTs or non-specialized English teachers, according to their own awareness of themselves as professionals. Nevertheless, the fact that they already possessed a body of pedagogic-related knowledge indicates two important things. First, the teachers in this context who do not have a specialized qualification in teaching English resort to their experiential, professional and personal knowledge, which they have accumulated along their professional careers, to commence a CoP. The second is that those knowledge sources converge to activate and orient the practices of the community, manifested in new ways of professional learning.

What follows is an analysis of the participation dynamics that emerged in the CoP. We first discuss the new forms of professional learning that resulted from participation in the practices of the community. We then focus on what was transformed, and the way participation is projected in the future in imagined CoP.

\subsection{Participation in the Community}

In the collaboration group, the NLELTs encountered an opportunity to express their concerns about the pedagogical processes in the school, but most importantly, about the way they could contribute by taking an active role in the improvement of those processes. In the dynamics of thinking about what that contribution could be, they decided that what happens inside the classrooms is significant for students to meet the pedagogical guidelines of the institution concerning the area of English. The participants decided that in order to hone their teaching practices, designing lessons and didactic materials in accordance with the class objectives and student knowledge of the world was the first collaborative work they would engage in. Everything happening in this community thereafter revolved around this form of participation. 
Planning lessons together meant the teachers thought thoroughly about not only how they were performing their teaching practices before joining the group, but also how they were performing them while constructing lessons collectively. As a consequence, there is a realization that their jointly planned lessons needed to be organized in a sequence and be better structured. The teachers converged on the idea that quality lessons needed to be informed by elements such as time management, and the organization of activities designed. Although it might seem elemental, this finding means that the teachers understand the practice beyond the act of planning a lesson. According to Johnson (1999), teachers in a social perspective of learning not only engage in learning about the procedural, technical aspects of teaching but also in reasoning about teaching. This means a deeper understanding of the practice in terms of who they are as teachers, their students and the context.

By understanding the dynamics of language practices framed within a problematic context, the NLELTs believe there are salient factors beyond the scope of what happens inside the classroom. They then see that there are curricular aspects that affect efforts to improve lessons. In this phase of the collaborative process, the participation starts to progress to how they can improve curricular content in the future, according to the information they have already learned about their working context. We understand this phenomenon as the moment in which the NLELTs teachers make informed future projections in the core of the community. Interestingly, such informed decisions are moving from the micro context of the classroom to the macro reality of the school, thus unveiling traces of the teachers' empowerment on a quest for transformations.

Now that the four teachers feel more empowered and the community has shifted from the nurturing of individual forms of knowledge to a process that unfolds within a participatory framework (Buysse, et al., 2003), the participants acknowledge that the transformations resulting from joint knowledge construction are given at the level they initially planned, which is the change in students' language learning progress. Most importantly, the teachers, at least in Geoff's case, were transformed through their actions and those of the other participants. Buysse et al. (2003) argue that from this relational perspective of persons and their actions within a socially and culturally constructed world, understanding and experience are in constant interaction. This finding is relevant, since according to Barab and Duffy (2000), a distinguishable characteristic of a CoP is the "development of self through participation in the community and the importance of legitimate participation as part of a community in that development of self" (p.35).

\subsection{Building Bridges towards Imagined Communities of Practice}

We believe the fact that the teachers imagine participating in hoped communities of practice is a far-reaching consequence of the idea that practitioners should work together to co-construct knowledge as part of a common enterprise, rather than through separate endeavors. We would like to argue that collegial talk and the knowledge derived from it have strong consequences in a teacher's development of investment. The aforementioned transformations could contribute to helping participants better interpret the avenues for change in the school, stimulating the building of bridges towards the imagined futures of sustained improvement and transformation.

The NLELTs can access those imagined communities and their practices due to the impact of current actual learning in the real community to which they belong. This has implications for the way that affiliation to desired communities is influenced by a teacher's empowerment to enact their role as a community member, as a result of engagement in actual collective practices. The findings here mean that imagined participation and imagined versions of themselves (imagined positioning as teachers) in the future are shaped by their engagement in present communities of practice, and the subsequent participation in constructing knowledge socially.

Overall, we demonstrated that research on imagined communities can be extended in the arena of professional teacher development, to the analysis of how teachers imagined participation in communities is collectively constructed in the present, when they take part in legitimate collective construction of knowledge.

\section{References}

Akbari, R., \& Moradkhani, S. (2012). Is a degree relevant? A comparison of pedagogical thought units of teachers with and without ELT-related academic credentials. Australian Journal of Teacher Education, 37(12), 77-93. https://doi.org/10.14221/ajte.2012v37n12.5

Anderson, B. (1991). Imagined communities: Reflections on the origin and spread of nationalism (Reved.). London: Verso.

Barab, S. A., \& Duffy, T. M. (2000). From practice fields to communities of practice. In D. H. Jonassen \& S. M. Land (Eds.), Theoretical foundations of learning environments (pp. 25-55). Mahwah, NJ: Lawrence Erlbaum Associates.

Borg, S. (2003). Teacher cognition in language teaching: A review of. Language Teaching, 36, 81-109. 
https://doi.org/10.1017/S0261444803001903

Borg, S. (2006). Teacher cognition and language education: Research and practice. London: Continuum.

Buysse, V., Sparkman, K., \& Wesley, P. (2003). Communities of practice: Connecting what we do with what we know. ProQuest Education Journals, 69(3), 263-278. https://doi.org/10.1177/001440290306900301

Cárdenas, M., González, A., \& Álvarez, J. (2010). In-service English teachers' professional development: Some $\begin{array}{lllll}\text { conceptual considerations } & \text { for } & \text { Colombia. } & \text { Folios, } & 31(3),\end{array}$ https://doi.org/10.17227/01234870.31folios49.67

Carmin, C. N. (1998). Issues on research on mentoring: Definitional and methodological. International Journal of Mentoring, 2(2), 9-13. Retrieved from https://eric.ed.gov/?id=EJ384929

Cheng, L., \& Wang, H. (2004). Understanding professional challenges faced by Chinese teachers of English. TESL-EJ, 7(4), 1-20.

Clarke, A. (2003). Situational analyses: Grounded theory mapping after the postmodern turn. Symbolic Interaction, 26(4), 553-576. https://doi.org/10.1525/si.2003.26.4.553

Cobb, P., Confrey, J., diSessa, A., Lehrer, R., \& Schauble, L. (2003). Design experiments in education research. Educational Researcher, 2(32), 9-13. https://doi.org/10.3102/0013189X032001009

Cochran-Smith, M. (1993). Inside/outside: Teacher research amd knowledge. New York: Teachers College Press.

Corbin, J., \& Strauss, A. (2015). Basics of qualitative research: Techniques and procedures for developing grounded theory. Thousand Oaks, CA: SAGE.

Correa, J. M., Martinez-Arbelaiz, A., \& Aberasturi-Apraiz, E. (2015). Post-modern reality shock: Beginning teachers as sojourners in communities of practice. Teaching and Teacher Education, 48, 66-74. https://doi.org/10.1016/j.tate.2015.02.007

Darling-Hammond, L. (2006). Powerful teacher education: Lessons from exemplary programs. San Francisco, CA: Jossey-Bass. https://doi.org/10.1177/0022487105283796

Diaz-Maggioli, G. (2003). Professional development for language teachers. ERIC Digest, EDO-FL-03-03.

Diaz-Maggioli, G. (2004). Teacher-centered professional development. Alexandria, VA: ASCD.

Diaz-Maggioli, G. (2012). Teaching language teachers: Scaffolding professional learning. Plymouth, UK: Rowman \& Littlefield Education.

Gailbraith, P., \& Anstrom, K. (1991). Peer coaching: An effective staff development model for educators of linguistically and culturally diverse students. Directions in Language Education, 1(3), 1-6.

Harteis, C., \& Gruber, H. (2004). Competence-supporting working conditions. In B. H .P. A. R. Bromme, \& H. Gruber (Eds.), Professional learning: Gaps and transitions on the way from novice to expert (pp. 251-270). Dordrecht: Kluwer. https://doi.org/10.1007/1-4020-2094-5_13

Hofer, B. (2001). Personal epistemology research: Implications for learning and teaching. Journal of Educational Psychology Review, 13(4), 353-383. https://doi.org/10.1023/A:1011965830686

Ivanic, R. (2006). Language, learning and identification. In Language, culture and identity (pp. 7-29). Equinox 23.

James, P. (2001). Teachers in action: Tasks for in-service language teacher education and development. Cambridge: Cambridge University Press.

Johnson, K. (1999). Understanding language teaching: Reasoning in action. Boston: Heinle \& Heinle. https://doi.org/10.1177/136216889900300301

Kanno, Y., \& Norton, B. (2003). Imagined communities and educational possibilities: Introduction. Journal of Language, Identity and Education, 2(4), 241-249. https://doi.org/10.1207/S15327701JLIE0204_1

Karimi, M. N. (2011). Variations in EFL teachers' pedagogical knowledge. The Journal of Teaching Language Skills (JTLS), 3(3), 84-114.

Kumaravadivelu, B. (2006). Understanding language teaching: From method to postmethod. Mahwah, NJ: Lawrence Erlbaum.

Lave, J., \& Wenger, E. (1991). Situated learning: Legitimate peripherial participation. Cambridge: Cambridge University Press. https://doi.org/10.1017/CBO9780511815355 
Liu, Y. (2013). The social organisation of talk-in-interaction at work in a language teacher professional community. Learning, Culture and Social Interaction, 2(3), 195-207. https://doi.org/10.1016/j.lcsi.2013.06.001

McNulty, F., \& Quinchía, D. (2007). Designing a holistic professional development program for elementary school English teachers in Colombia. Profile, 8(1), 131-143.

Merriam, S. B. (2009). Qualitative research: A guide to design and implementation. San Francisco: Jossey-Bass Publications.

Ministerio de Educación Nacional. (1979). Decreto No. 2277-1979. Estatuto docente. Colombia. Retrieved from http://www.mineducacion.gov.co/1621/articles-103879_archivo_pdf.pdf

Norton, B. (2001). Non-participation, imagined communities and the language classroom. In M. Breen. (Ed.), Learner comtributions to language learning: New directions in research (pp. 159-171). London: Longman/Pearson Education.

Norton, B. \& Toohey, K., (2002). Identity and language learning. In R. Kaplan (Ed.), The Oxford Handbook of Applied Lingusitics. New York: Oxford University Press.

Paavola, S., Lipponen, L., \& Hakkarainen, K. (2004). Models of innovative knowledge communities and three metaphors of learning. Review of Educational Research, 74(4), 557-576. https://doi.org/10.3102/00346543074004557

Papineau, S. (2017). Special education teacher perceptions of effectiveness and knowledge in literacy instruction: Implications of literacy coaching (Doctoral dissertation).

Pavlenko, A., \& Norton, B. (2007). Imagined communities, identity, and English language learning. In J. Cummins, \& C. Davidson (Eds.), Kluwer Handbook of English Language Teaching (pp. 669-680). Dordrecht, Netherlands: Springer. https://doi.org/10.1007/978-0-387-46301-8_43

Richards, J. C., \& Lockhart, C. (1994). Reflective teaching in second language classrooms. New York: Cambridge University Press. https://doi.org/10.1017/CBO9780511667169

Richards, J., \& Farrell, T. (2005). Professional development for language teachers: Strategies for teacher learning. New York: Cambridge University Press. https://doi.org/10.1017/CBO9780511667237

Sanchez, H. S. (2011). El impacto de las experiencias previas de aprendizaje de una segunda lenguaen la formación de profesores de idioma extranjero. Revista de Educación, 3(7), 121-143.

Schneider, A., \& Kipp, K. H. (2015). Professional growth through collaboration between kindergarten and elementary school teachers. Teaching and Teacher Education 52, 37-46. https://doi.org/10.1016/j.tate.2015.08.006

Schön, D. A. (1983). The reflective practitioner: How professionals think in action. New York: Basic Books.

Shin, S. (2016). English language teaching as a second career. Bristol, UK: Multilingual Matters. https://doi.org/10.1093/elt/ccv070

Toohey, K. (2000). Learning English at school: Identity, social relations and classroom practice. Clevedon, England: Multilingual Matters.

Trent, J., Gao, X., \& Gu, M. (2014). Language teacher education in a multilingual context: Experiences from Hong Kong. New York: Springer. https://doi.org/10.1007/978-94-007-7392-9

Vandevoort, L., Amrein-Beardsley, A., \& Berliner, D. (2004). National board certified teachers and their students' achievement. Education Policy Analysis Archives, 12(16). 1-117. https://doi.org/10.14507/epaa.v12n46.2004

Veirty, D. (2011). The reverse move: Enriching informal knowledge in the pedagogical grammar class. In K.E. Johnson and P.R. Golombek (Eds.), Research on second language teacher education: A sociocultural perspective on teacher professional development (pp.153-167). New York: Routledge.

Wallace, M. (1991). Training foreign language teachers: A reflective approach. Cambridge: Cambridge University Press.

Weinstein, C. (1990). Prospective elementary teachers' beliefs about teaching: Implications for teacher education. Teaching and Teacher Education, 6(3), 279-290. https://doi.org/10.1016/0742-051X(90)90019-2

Wenger, E. (1998). Communities of practice: Learning, meaning and identity. Cambridge, England: Cambridge 
University Press. https://doi.org/10.1017/CBO9780511803932

Widodo, A. (2017). Experienced biology teachers' pedagogical content knowledge (PCK) on photosynthesis. AIP Conference Proceedings, 1848(1), 1-4. https://doi.org/10.1063/1.4983985

\section{Copyrights}

Copyright for this article is retained by the author(s), with first publication rights granted to the journal.

This is an open-access article distributed under the terms and conditions of the Creative Commons Attribution license (http://creativecommons.org/licenses/by/4.0/). 